\title{
TRANSDISCIPLINARIDADE E ATIVISMO CIENTÍFICO COMO CUNHAS PARA ACELERAR O DESENVOLVIMENTO AMAZÔNICO
}

\section{ENSAIO TEÓRICO}

FONSECA, Claudio Ruy Vasconcelos da ', SANTIAGO, Sandro Breval 2, PAULA, Estevão Vicente Cavalcante Monteiro de ${ }^{3}$

FONSECA, Claudio Ruy Vasconcelos da. SANTIAGO, Sandro Breval. PAULA, Estevão Vicente Cavalcante Monteiro de. Transdisciplinaridade e ativismo científico como cunhas para acelerar o desenvolvimento amazônico. Revista Científica Multidisciplinar Núcleo do Conhecimento. Ano. 07, Ed. 01, Vol. 04, pp. 254278. Janeiro de 2022. ISSN: 2448-0959, Link de acesso: https://www.nucleodoconhecimento.com.br/biologia/desenvolvimentoamazonico

\section{RESUMO}

Estudar e conhecer a Amazônia diante do cenário socioeconômico atual leva à reflexão sobre a eficácia das metodologias científicas adotadas. Estaria o diálogo entre grupos de pesquisas e os tomadores de decisões permitindo a produção de conhecimento robusto e adequado às demandas do setor produtivo amazônico, e articulado de modo a sensibilizar a academia a se debruçar sobre os gargalos tecnológicos existentes, bem como, novas oportunidades para o aproveitamento da riqueza natural? Foi realizada uma análise nas exigências de editais de fomento científico produzidos pelas principais instituições de fomento e desenvolvimento na

${ }^{1}$ Doutor. ORCID: 0000-0002-1955-288X

2 Doutorado. ORCID: https://orcid.org/0000-0002-0184-9845

${ }^{3}$ Doutorado. ORCID: 0000-0002-9913-2403

RC: 105297

Disponível em: https://www.nucleodoconhecimento.com.br/biologia/desenvolvimento$\underline{\text { amazonico }}$ 
Amazônia, nos últimos dois anos, e verificou-se que a epistemologia predominante é a disciplinaridade, fato que torna a aplicação dos resultados mais restrita. A escala temporal da produção científica, velocidade de impacto na sociedade em relação à sua aplicação, a linguagem adequada e a falta de percepção da sociedade sobre a incerteza da política, são fatores importantes que afetam a relação entre a academia e os formadores de opinião e políticas públicas, sendo necessário intensificar um certo ativismo científico, advindo da aplicação da epistemologia translacional. Em paralelo, o gerenciamento da governança do conhecimento científico se daria, em alguns casos, com maiores probabilidades de sucesso com a utilização de algoritmos que ainda são timidamente adotados no meio acadêmico da Amazônia.

Palavras-chave: Transdisciplinaridade, Sociedade, Ciência amazônica, Transferência tecnológica.

\section{INTRODUÇÃO}

A ciência procura responder perguntas bens formuladas para dirimir as dúvidas da sociedade. Perguntas bem formuladas têm focos bem definidos. Ironicamente, muitas vezes o resultado das pesquisas estabelece novas perguntas. Não obstante, existem ainda emaranhados complexos de situações relacionadas com o comportamento do cientista, a relação da ciência com a sociedade, seus protocolos e métodos científicos que precisam ser analisados para entender o que se produz e como se produz conhecimento, especificamente no Estado do Amazonas. Este trabalho objetiva verificar a razão por que o conhecimento produzido na academia amazônica tem sido pouco útil para respaldar soluções requeridas por problemas complexos. A questão norteadora é: estaria o diálogo entre grupos de pesquisas e os tomadores de decisões permitindo a produção de conhecimento robusto e adequado às demandas do setor produtivo amazônico, e articulado de modo a sensibilizar a academia a se debruçar sobre os gargalos tecnológicos existentes, bem como, novas oportunidades para o

RC: 105297

Disponível em: https://www.nucleodoconhecimento.com.br/biologia/desenvolvimento$\underline{\text { amazonico }}$ 
aproveitamento da riqueza natural? A metodologia empregada foi uma análise dos últimos dois anos, de editais de fomento científico, produzidos nas principais instituições de fomento amazônicas, para verificar se já está se consolidando a epistemologia translacional, considerando a complexidade amazônica que exige respostas mais holísticas às demandas regionais paradigmáticas e dos setores mais aplicados.

\section{PROTOCOLOS CIENTíFICOS SÃO SUFICIENTES PARA A SOLUÇÃO DOS PROBLEMAS?}

Cientistas são, geralmente, vistos como indivíduos separados da sociedade, vivendo em laboratórios isolados, buscando conhecimentos não relevantes ao dia a dia da sociedade. São satirizados muitas vezes por apresentadores de talk shows que relatam títulos de pesquisas completamente desfocados do viés da utilidade, como por exemplo, "Variação da temperatura retal de papagaios do lago X", levando o público a criar um conceito de excentricidade acadêmica. Todavia, há contra perspectivas, pelo menos no que diz respeito à relevância prática da pesquisa acadêmica (BASSETT, 2020). É o caso, por exemplo, das sinergias e repercussões entre universidades e desenvolvimentos de pesquisas de alta tecnologia, como é o caso do Vale do Silício na Califórnia, da Rota 128 em torno de Boston e do triângulo Raleigh-Durham, da Embraer, Fundação Boticário, Embrapa e Fiocruz. Essas sinergias, no entanto, relacionam-se com desenvolvimentos práticos em áreas como tecnologia da informação e pesquisa de biomateriais, biotecnologia, fármacos. $\mathrm{Na}$ área de desenvolvimento de políticas sociais e públicas, raramente são feitas as ligações entre pesquisa acadêmica e desenvolvimento de políticas.

Embora as questões e problemas instantâneos possam mudar com o tempo, a necessidade de pesquisa sobre questões fundamentais é contínua. Embora os formuladores individuais de políticas geralmente tenham horizontes de tempo curtos,

RC: 105297

Disponível em: https://www.nucleodoconhecimento.com.br/biologia/desenvolvimentoamazonico 
o processo de pesquisa necessita de escalas mais amplas de tempo, uma circunstância pouco acolhedora, uma vez que a produção acadêmica não pode responder de forma imediata aos políticos.

As questões fundamentais são de extrema importância para solucionar problemas emergentes. Atualmente, com as bases de conhecimento sobre vírus, pesquisadores de diversos lugares do mundo estão desenvolvendo soluções clínicas para o combate a este novo tipo de coronavírus (COVID-19) (BASSETT, 2020). No entanto, no caso amazônico, os editais não estão estimulando pesquisas em grupos transdisciplinares, fato que será abordado a seguir.

\section{A PESQUISA ACADÊMICA AFETA AS DECISÕES POLÍTICAS? DEVEM OS ACADÊMICOS CONSENTIR EM CERTO ATIVISMO PARA PRODUZIREM IMPACTO NOS TOMADORES DE DECISÕES?}

As palavras utilizadas por um certo ministro da Saúde dando ênfase em esperar a resposta cientifica para tomada de decisão política por parte do Estado, torna-se um recurso para reduzir conflitos secularmente conhecidos. Segundo Mitre (2016), Maquiavel alerta que "os conselhos baseados em ideais normativos irão enfraquecer o príncipe" e os "conselhos realísticos [....] irão fortalecê-los".

A aproximação entre fatos citados por Mitre (2016) como a matéria prima das ciências, e valores considerados pelo mesmo autor como a substância do conflito político é o desafio da sociedade atual que começou a entender que, dado os avanços tecnológicos os conflitos sociais e econômicos com grande aderência mundial só se resolverão com a ciência. Assim, aquela ciência que não participa em discussão de política pública está fadada a morrer para sociedade em geral.

Esta participação se dará com o ganho da respeitabilidade como consequência da produção de trabalhos científicos de alta qualidade e que sejam respaldo eficazes RC: 105297

Disponível em: https://www.nucleodoconhecimento.com.br/biologia/desenvolvimentoamazonico 
na área política. A pesquisa deve ser sintetizada e traduzida para uma linguagem que seja entendida pelos formuladores de políticas, pelo público em geral e pela mídia (GUNDERSON, 2007).

A sociedade cientifica também deve estar preparada para resgatar o acervo de informação e conhecimento produzido ao longo do tempo para responder demandas emergentes. Cita-se aqui o fato em que se vive atualmente com a nova COVID19. Apesar de nova, já existe massa crítica com informações e conhecimentos que possibilitam desvendar, a passos largos, os seus segredos criando assim uma expectativa positiva de que em breve existirá um remédio que tratará eficientemente a COVID-19 (OGBURN et.al., 2020).

Isto traz à tona, a explicação sobre o que Kuhn (2012) chama de ciência normal, ou seja, pesquisa firmemente embasada em uma ou mais realizações passadas e que são reconhecidas por algum tempo pela comunidade científica como proporcionando os fundamentos para práticas posteriores. É exatamente essa base que promove avanços, forma a atividade dos laboratórios em tempos menos atribulados.

Mais importante ainda é a existência de exemplos de como acúmulos de resultados podem produzir avanços significativos. Uma nova disciplina denominada Cientometria analisa como os vários resultados publicados por diferentes pesquisadores e instituições podem ser agrupados para produzir conhecimento sobre constantes e algoritmos que estavam ocultos, mas que são importantes para o meio acadêmico, para economia, entre outros (SILVA et al., 2001).

No entanto, ainda resta pensar em estratégias precisas que ajudem a incrementar o valor das pesquisas dando mais visibilidade ao pesquisador e seu trabalho (ZULUAGA, 2017). O que se pretende é sistematizar resultados, organizar a produção do conhecimento, assuntos que abrem possibilidades para inovações que causem impacto econômico e político. Porém, o exercício cientométrico tem motivado a RC: 105297

Disponível em: https://www.nucleodoconhecimento.com.br/biologia/desenvolvimento$\underline{\text { amazonico }}$ 
valorização de certas ciências que garantem lucro empresarial, em detrimento de outras que vão pavimentando discretamente o conjunto de conhecimentos necessários para se compreender e gerenciar aspectos da vivência humana que são complexos e que exigem a chamada pesquisa básica.

A interação entre o meio científico e formadores de opiniões e políticas constrói um diálogo de extrema importância para o sucesso de um país desenvolvido e tecnologicamente avançado, e isto se dá dentro de peculiaridades e características assim sintetizadas:

a) Os horizontes temporais no processo de pesquisa são diferentes do da política. As pesquisas que são motivadas por uma preocupação política podem atingir o domínio público somente após o interesse político. Obviamente, a aceitação política é um ingrediente-chave. Há simplesmente tempos e condições em que o processo político não será alterado pelos resultados da pesquisa, e outras vezes em que estará aberto a mudanças que podem ser afetadas por essa pesquisa (GUNDERSON, 2007). Aaron (1978) diz que a pesquisa, em dados momentos, reflete os humores políticos dominantes, mas, também influencia politicamente. Heineman et al. (1997) levantam a preocupação de que a pesquisa possa perder sua credibilidade se for considerada uma "mercadoria a ser comprada e vendida" e que, neste caso, "a análise principalmente para o reforço de escolhas já feitas parece ser uma característica comum da realidade política". Os autores salientam a força coerciva que a pesquisa acadêmica pode sofrer quando financiada para apoiar políticas específicas. Tal é o perigo ao qual podem estar expostas as instituições de pesquisas no atual momento, quando uma pandemia exacerba credos políticos.

A correção para o problema acima parece estar ligada à necessidade de os próprios pesquisadores, muitas vezes, estarem envolvidos no processo de formulação de políticas em algum momento de suas carreiras. Este tema foi ecoado por outros

RC: 105297

Disponível em: https://www.nucleodoconhecimento.com.br/biologia/desenvolvimento$\underline{\text { amazonico }}$ 
pesquisadores tal como Lynch (2005), um acadêmico que serviu como economistachefe no Departamento de Trabalho dos EUA de 1995 a 1997. Porém, há um certo consenso de que cientistas importantes que ocupam altas apostas na comunidade acadêmica não perdem tempo com formulação de políticas. Talvez, seja esse um dos motivos de haver um déficit no impacto dos resultados científicos nas tomadas de decisões.

b) A pesquisa cujo resultado impacta diretamente a sociedade torna-se muito mais fácil para transformar-se em política pública do que aquela cujo benefício social seja indireto (CARNEIRO et al., 2018). A percepção da sociedade sobre a contribuição da ciência à política pública gerada na área ambiental é muito mais difícil do que aquela gerada para área da saúde e engenharia em geral, mesmo porque na área ambiental existem interesses diferentes entre os segmentos sociais e econômicos.

c) Há dificuldade da sociedade no entendimento de que o tempo de resposta para solução de problemas está associado às variáveis envolvidas na análise da pesquisa, a escala temporal que precisa ser considerada e a multidisciplinaridade necessárias para produzir informações e gerar conhecimentos robustos que tragam soluções confiáveis.

d) Há falta de percepção da sociedade sobre a incerteza da ciência e que a pesquisa procura diminuir ao máximo o nível de incerteza (LOMBARDI et al., 2010). Atualmente vive-se o drama da cloroquina, pois a angústia da população em receber respostas positivas da ação do medicamento contra a COVID-19 faz com que o público pressione pesquisadores para uma resposta rápida. Acontece que são tantas as variáveis envolvidas no processo de desenvolvimento de um remédio, que leva um pouco de tempo para obter um resultado com nível de incerteza dentro de um intervalo de confiança estatisticamente aceitável.

RC: 105297

Disponível em: https://www.nucleodoconhecimento.com.br/biologia/desenvolvimentoamazonico 
e) Na sociedade da informação o público praticamente acompanha, em tempo real, o desenvolvimento de trabalhos científicos e está informado das dificuldades naturais de um processo de pesquisa, assim como resultados parciais (FACULDADE DE MEDICINA DA UNIVERSIDADE FEDERAL DE MINAS GERAIS, 2020). Tal transparência cria incerteza sobre o que se está descobrindo.

f) A polarização da política está tentando ideologizar a ciência colocando a absurda ideia de que a descoberta cientifica é revelada em consonância com a dominância do ambiente político em que se encontra o país (INSTITUTO PARA O DESENVOLVIMENTO DO JORNALISMO, 2015).

\section{NEUTRALIDADE DA CIÊNCIA}

Ainda que possa ser um tema recorrente, deve-se enfatizar que a neutralidade da ciência é lenda. O cientista é um ser humano e, como tal, um ser social que é afetado pelas suas relações humanas, sociais e políticas. A ação política no meio da atividade cientifica é fortemente recrudescida no financiamento e na divulgação cientifica.

Os problemas contemporâneos passam a ser as pesquisas dominantes para as instituições de ensino, pesquisas e de educação. Às vezes, demandas cientificas de países mais avançados, com modos de vida diferenciados e com distintas facilidades operacionais, passam a ser prioridades cientificas internacionais.

Ao longo do tempo, observa-se concentrações de grupos de pesquisas de diferentes áreas em temas de relevância da época. Isto se dá em virtude de as agências financiadores priorizarem pesquisas relevante para o momento social, político e econômico de uma determinada época. Portanto, as mudanças das áreas de pesquisas nem sempre se dão pela saturação de pesquisas sobre um determinado objeto de pesquisa, mas pela oportunidade de recursos oferecidos pelos agentes de fomento. Isto provoca vazios dentro da cadeia de conhecimento de uma pesquisa.

RC: 105297

Disponível em: https://www.nucleodoconhecimento.com.br/biologia/desenvolvimentoamazonico 
É importante enfatizar o efeito da sociedade de informação sobre a ciência, pesquisa e inovação. Maffesoli (1998) explica que a sociedade pós-moderna é constituída de constelações de tribos, cujos membros buscam as suas sobrevivências formando-se em massa para lutar no que acreditam. Às vezes, são aldeias Globais nas quais seus membros, em geral não se conhecem, mas militam por causa própria sem conhecer profundamente as causas que defendem, mas que são influenciadas principalmente pela mídia. Isto faz com que de maneira organizada pressionem os poderes legislativo, judiciário e executivo locais, colocando em riscos pesquisas de interesses relevantes para a ciência e para o país. Vale lembrar que as Academias de Ciência dos Estados Unidos e da Inglaterra quase foram proibidas de desenvolverem pesquisas em células tronco pelos seus congressistas (FALCÃO, 2005). A partir daí o segmento científico percebeu que não trabalha para sociedade, mas com a sociedade, e resolveu investir na popularização da ciência.

Ao mesmo tempo, a sociedade atual evoluída tecnologicamente, começou acreditar, cada vez mais na ciência. Este crescente consenso da sociedade coloca a Ciência como um ator importante para dar suporte às decisões políticas, causando impactos sociais capazes de gerar polemicas nacionais e até em nível mundial. Isto lembra um pouco da expressão de Leff (2002), no seu trabalho sobre epistemologia ambiental, de que "Meio Ambiente não é ecologia [...], mas a relação entre poderes sobre a forma dominante de conhecimento...". É importante nos debates globais entre nações o conhecimento aprofundado sobre o objeto em discussão, para que os acordos tenham melhores equidades sociais e econômicas entre os países.

Esta expectativa positiva da sociedade pós-moderna em relação à ciência pressiona a academia e instituições de pesquisas por respostas, as mais rápidas possíveis, para os problemas sociais e econômicos da atualidade. Assuntos relativos à produção de conhecimento para a saúde, meio ambiente e negócios fazem parte dos clamores diários da sociedade pós-moderna. Ironicamente, não se aceitam erros de

RC: 105297

Disponível em: https://www.nucleodoconhecimento.com.br/biologia/desenvolvimento$\underline{\text { amazonico }}$ 
pesquisadores, como se suas hipóteses fossem sempre acuradamente certas, e quando os resultados de uma pesquisa são publicados, eles sofrem extremas pressões daquelas "tribos" cuja percepção do objeto de estudos seja distinta.

\section{MÉTODOS TRANSLACIONAIS SÃO MELHORES QUE OS DISCIPLINARES?}

Cientistas formados na segunda metade do século XX aprenderam, em sua maioria, a construir conhecimento de forma quase solitária. Era o método disciplinar da subespecialização, onde problemas muito focados eram encarados e, posteriormente poderiam ser adicionados ao corpo de conhecimentos já existentes. Por essa razão, há grande quantidade de editais que permitem pesquisa individual e, consequentemente, publicações em autoria solitária. Todavia, com a construção da globalização e do comércio multinacional, os problemas ambientais e sociais saíram "das aldeias" e tornaram-se amplos e complexos, exigindo que as disciplinas isoladas se aproximassem, contribuindo para o surgimento da metodologia interdisciplinar. Assim, as pesquisas científicas começaram um novo modus operandi onde uma série de disciplinas teriam que operar juntas, porém mantendo seus métodos e suas próprias perguntas. Essa nova maneira de criar conhecimento começou a perpassar outras atividades profissionais. (CENTRE FOR EDUCATIONAL RESEARCH - CERI, 1972).

Balsiger (2004) estabelece que o método interdisciplinar abrange uma série de disciplinas e que não está restrito às pesquisas cientificas, mas ao ensino e práticas profissionais. No entanto, a abordagem interdisciplinar não é suficiente para o entendimento mais fidedigno da realidade, porque se limita a uma mescla de disciplinas que se mantém quase sem articulação, não propiciando a desejada coerência para observações mais amplas da complexidade. Essa perspectiva deu surgimento ao método transdisciplinar, no qual o conhecimento final é mais do que a

RC: 105297

Disponível em: https://www.nucleodoconhecimento.com.br/biologia/desenvolvimento$\underline{\text { amazonico }}$ 
soma de suas disciplinas, e sim a fusão das disciplinas (LAWRENCE, 2004). A transdisciplinaridade implica uma tensão entre as disciplinas, enquanto multidisciplinaridade ou interdisciplinaridade simplesmente implica a juntura de diferentes tipos de conhecimentos. A transdisciplinaridade não deve simplificar a realidade apenas lidando com partes dela que são compatíveis no cruzamento de múltiplas perspectivas disciplinares, como é, em muitos casos, a pesquisa interdisciplinar. A transdisciplinaridade atua ao mesmo tempo entre as disciplinas ultrapassando-as, compondo assim todos os processos da multidisciplinaridade e Interdisciplinaridade (RAMADIER, 2004).

$\mathrm{Na}$ transdisciplinaridade as ações são destinadas a transformar o ambiente construído em resolução de problemas multidimensionais. Assim, a capacidade para solucionar problemas complexos é diretamente proporcional a coparticipação eficaz entre cientistas, profissionais, tomadores de decisões, numa tentativa de fechar uma lacuna de aplicabilidade em setores que lidam com o ambiente natural e o ambiente humano. Está-se falando de uma necessidade premente de investidas inovadoras, de modo a arquitetar uma sociedade onde o bem-estar social esteja acessível a todos (LAWRENCE et al., 2004).

A transdisciplinaridade lida com dificuldades de pesquisas e organizações que lidam com esferas complexas e heterogêneas. Este modo de produção de conhecimento também é caracterizado por sua natureza híbrida, não linearidade com grande dose de reflexividade, transcendendo qualquer estrutura disciplinar acadêmica (BALSIGER, 2004). Segundo Lawrence et al. (2004) a transdisciplinaridade desafia a fragmentação do conhecimento, aceita contextos locais e incertezas, implica em ação intercomunicativa que exige estreita e contínua colaboração durante todas as fases de um projeto de pesquisa; é frequentemente orientada para a ação. Isso implica articular os vários limites disciplinares, mas também articular o desenvolvimento teórico com as práticas profissionais. Aportes transdisciplinares frequentemente lidam

RC: 105297

Disponível em: https://www.nucleodoconhecimento.com.br/biologia/desenvolvimentoamazonico 
com o mundo real e geram conhecimentos que não só abordam problemas sociais, mas também contribuem para sua solução.

$\mathrm{Na}$ atualidade do orbi, onde pandemias e catástrofes acontecem cada vez com maior frequência, as instituições de pesquisas e de fomento, mormente as nacionais, terão que traçar um futuro mais consolidado na transdisciplinaridade. A resistência orgânica das instituições que perpetuam seus departamentos não poderá ser suficiente para ajudar na produção de conhecimento consentâneo com a complexidade dos problemas, quer sejam naturais ou aqueles oriundos da atividade humana.

\section{AMAZÔNIA: PESQUISAS BÁSICAS E APLICADAS, SERVIÇOS TÉCNICOS CIENTÍFICOS, DESENVOLVIMENTO TECNOLÓGICOS OU PESQUISA TRANSLACIONAL?}

Nos dias de hoje, com os desafios da sociedade, a procura de respostas através da ciência aos grandes problemas nacionais e internacionais, cabe questionar qual é o melhor caminho para prover os diversos segmentos sociais e econômicos de informações e conhecimentos para melhorar a qualidade de vida das populações locais.

No caso amazônico, apesar dos esforços, ainda se produz conhecimento disciplinar em quantidade maior do que o transdisciplinar, sendo que os editais de fomento não trazem nenhuma exigência para projetos translacionais.

Há premente necessidade de criação de ambiente transdisciplinar, sob pena de prejuízos monstruosos no futuro. Entidades de fomento à pesquisa na Amazônia ainda não viram a necessidade, mais que urgente, de iniciar discussões e treinamentos para o surgimento de grupos transdisciplinares. Falta visão contemporânea de ciência e das oportunidades.

RC: 105297

Disponível em: https://www.nucleodoconhecimento.com.br/biologia/desenvolvimento$\underline{\text { amazonico }}$ 
No entanto, registra-se uma primeira tentativa de desenvolver pesquisa translacional no Amazonas, com a iniciativa dos técnicos da Secretaria Executiva de Ciência, Tecnologia e Inovação do Estado do Amazonas (SECTI) em 2008. Neste referido ano, a SECTI propôs a constituição da Plataforma de translação para P, D \& I com o sentido de consolidar um sistema de conversão do conhecimento em produto ou processo. Assim, espera-se reverter a situação atual em termos de tecnologia para agregação de valor sobre os recursos naturais do Amazonas. No desenho dessa proposta, diante dos estudos realizados pela SECTI sobre a competência, a capacitação e a tecnificação existentes no Estado, foram propostas duas ações imediatas: a) Indução de Políticas Públicas de Capacitação para o Desenvolvimento Tecnológico; b) Promoção de um conjunto de processos técnicos e gerenciais robustos, que trazem agilidade e rastreabilidade ao caminho da ciência básica, à tecnologia e depois ao desenvolvimento de produtos e ao mercado.

A psicultura foi uma das áreas em que foi dada ênfase no citado estudo, com o objetivo de incrementar sua produção, a qualidade do produto para acréscimo de novos mercados. Diante da ótica de pesquisas translacionais foi rastreado todo o caminho da ciência e do desenvolvimento tecnológico sobre rações para peixe produzidas no Estado. Tal estudo envolveu massa crítica, capacidade tecnológica, segmentos existentes e chegou-se à conclusão de que o Estado não tem massa crítica para o desenvolvimento tecnológico em relação ao aproveitamento econômico do que tem sido gerado cientificamente. A avaliação translacional possibilitou observar os vazios na cadeia de conhecimento, fato que impossibilita que a informação esteja disponível ao mercado.

A aplicação de pesquisas translacionais apresentada como proposta para acelerar o desenvolvimento socioeconômico do Estado do Amazonas, no âmbito do projeto de Matriz produzida pela equipe técnica da Secretaria de Estado de Desenvolvimento Econômico, Ciência, Tecnologia e Inovação (SEPLANCTI), baseia-se em um amplo

RC: 105297

Disponível em: https://www.nucleodoconhecimento.com.br/biologia/desenvolvimentoamazonico 
estudo sobre o perfil da produção de conhecimento na academia e instituições de pesquisas locais. Este estudo revelou uma melancólica triste realidade relacionada à produção de pesquisas no Estado; concentração na pesquisa básica e/ou exploratória com pouquíssima ação em pesquisa aplicada e desenvolvimento tecnológico. No sentido de vencer a inércia atual da produção cientifica, convertendo de forma mais rápida possível o conhecimento em nota fiscal, sugere-se utilizar o método translacional. Para a compreensão simples sobre as pesquisas, os técnicos apresentaram a plataforma de translação para P, D \& I para o desenvolvimento da bioeconomia no Estado do Amazonas (fig. 1). 
Figura 1 - Plataforma de translação para Pesquisa, Desenvolvimento e Inovação

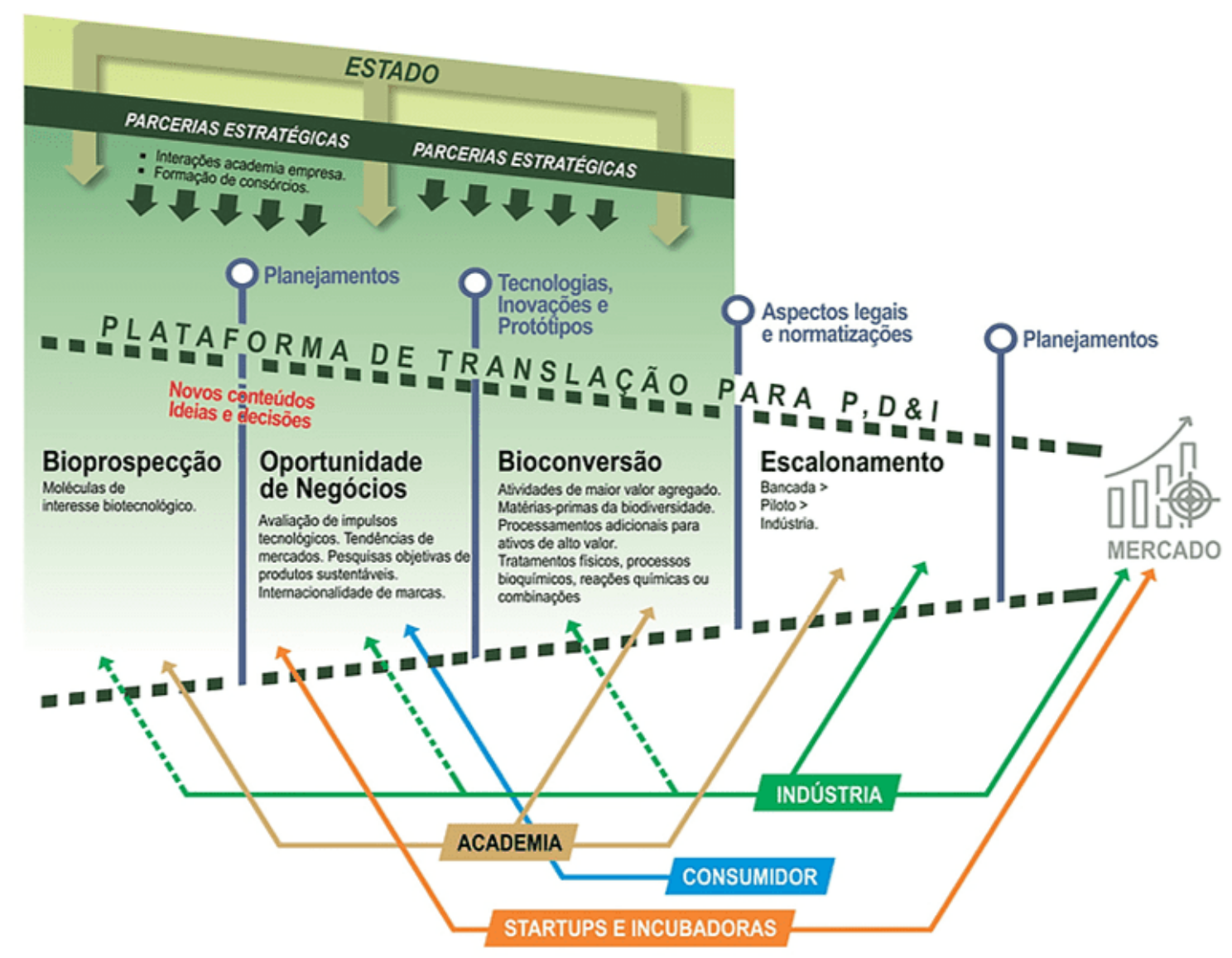

Fonte: SEPLACTI, 2008.

\section{MODELOS FUNDAMENTADOS}

É interessante perceber que na história do desenvolvimento da ciência, as análises e processos científicos evoluíram de acordo com a inovação tecnológica. Antes era um processo empírico, veio a ideia cartesiana, e com o advento de equipamentos que facilitam os manuseios das informações, apareceram a modelagem e agora a eScience, que tem como base a utilização de volumes de dados significativos obtidos

RC: 105297

Disponível em: https://www.nucleodoconhecimento.com.br/biologia/desenvolvimento$\underline{\text { amazonico }}$ 
em tempo real, possibilitando obter conhecimento sobre um objeto de estudo da forma mais real possível.

Mas, diferente do que se pode imaginar, não se faz ciência sem aplicação de uma metodologia adequada que adote uma racionalidade lógica procurando responder perguntas bem definidas. Por outro lado, a natureza não é departamentalizada, mas é o resultado de uma série de fenômenos físicos, químicos, biológicos que ocorrem concomitantemente dentro de uma complexidade difícil de ser teorizada. Assim, deve-se procurar uma conexão, mais próxima possível, entre a teoria e a realidade; portanto, é necessária uma visão mais holística da natureza e do conhecimento. Neste contexto, a modelagem, diante dos instrumentos atualmente existentes para experimentação e análise de dados, é o mecanismo mais adequados para encontrar a resposta, mais precisa possível, sobre o mundo em que se vive.

Através da atividade científica é possível a construção conceitual do mundo por meio de representações simplificadas e idealizadas de sistemas aceitos por comunidades cientificas.

A ciência como atividade investigativa é essencialmente social, aplicando-se ao melhoramento do meio que nos cerca, seja o natural ou artificial, através da invenção e manufatura de bens materiais ou culturais, convertendo-se em tecnologia, podendo ser considerada uma atividade produtora de novas ideias. As características fundamentais do labor científico são a racionalidade e objetividade.

A racionalidade corresponde aos conceitos, interpretações e raciocínios, que podem combinar-se obedecendo a um conjunto de regras lógicas que permitem chegar-se a novas noções, enquanto a objetividade busca alcançar a verdade; verifica a adaptação das ideias aos fatos recorrendo a um trabalho composto pela observação, a qual é controlável, e a experimentação que, até certo ponto, é reproduzível. Portanto, o conhecimento científico racionaliza a experiência não limitando-se a descrevê-la, ou

RC: 105297

Disponível em: https://www.nucleodoconhecimento.com.br/biologia/desenvolvimento$\underline{\text { amazonico }}$ 
seja, não é suficiente inventariar fatos, mas, explicá-los por meio de hipóteses e sistemas de leis chamados teorias.

Brandão et al. (2011) explicam que os cientistas não correm atrás de receitas infalíveis para construir modelos fundamentados na realidade e que refletem os fatos, dentro de um contexto de validade, com desejável grau de precisão. Justi et al. (2002) mostram que aprender Ciência significa conhecer os modelos idealizados pelos cientistas, como também as teorias, as leis que estão embasando os princípios e os conceitos usados em suas estruturas lógicas. Logo, é necessário refletir sobre os modelos científicos buscando entender suas funções e limitações, processo que torna possível testar e expressar novas modelagens, algo que está na base da formação de conhecimentos nas ciências da natureza. Em outras palavras, a ciência objetiva apreender a realidade através do raciocínio (BUNGE, 1960).

Brandão et al. (2011, p. 513) dizem que:

Em suma, o processo de modelagem científica reside no fato de que teorias gerais, que em princípio não se pronunciam diretamente sobre a realidade, ao acolherem modelos conceituais, produzem representações de parte da realidade, ou seja, modelos teóricos que fornecem soluções a situações-problema particulares.

A atividade de construção de modelos teóricos depende do conhecimento disponível e das habilidades do cientista. No dizer de Bunge (1989) modelos teóricos são esquemas que deverão ser enxertados sobre uma teoria, a qual deverá ser confrontada com os fatos.

Um levantamento da literatura científica nacional nos permitirá ver que há poucos trabalhando na modelagem de cenários. Tal ausência compromete nossa capacidade criativa quando confrontada por circunstâncias inesperadas. Esse problema está ligado a ausência de grupos transdisciplinares que possam buscar modelos, antecipando prováveis transtornos. Sem dúvida, há um acervo considerável de

RC: 105297

Disponível em: https://www.nucleodoconhecimento.com.br/biologia/desenvolvimento$\underline{\text { amazonico }}$ 
conhecimento gerado por décadas de investimento, mas será importante que sejam sistematizados dando ensejo a modelagens preditivas.

A mudança da realidade nacional, e em especial do Amazonas, relativa ao ponto de vista de modelagem, requer voltar aos bancos da universidade e fortalecer cursos entre os quais os de matemática, física e estatística. A didática deve ser atualizada, contextualizando a atuação destes conhecimentos às realidades atuais, onde o conhecimento representado por modelagem consistente precisa ser desenvolvido com corpo de pesquisadores de diferentes áreas do conhecimento.

Ressente-se ainda, em alguns casos, no desenvolvimento de projetos de pesquisa, um desenho de experimento cientificamente adequado, incorporando as variáveis envolvidas e contribuições de outras áreas do conhecimento. Infelizmente ainda hoje, existem pesquisadores que insistem desenvolver isoladamente o seu trabalho científico o que evidentemente resultará em um produto de prateleira. Atualmente, o mundo científico e segmentos públicos e privados valorizam a ciência produzida por grupos de cientistas transdisciplinares e translacionais.

Neste contexto, vale ainda salientar o aumento exponencial de produção de dados científicos nas diferentes áreas do conhecimento, transformando a comunicação acadêmica. A partir dos lugares mais longínquos do mundo é possível acessar dados, trocar informações e conhecimentos em tempo real, de maneira que o conhecimento produzido seja agilizado e a resposta do seu esforço de pesquisa tenha mais consistência.

Os governos e as agências de financiamento de pesquisas já contam com o aumento de acesso aos dados e publicações como meio de aumentar os ritmos das pesquisas. O que assusta, no caso amazônico, e que serve de alerta para os jovens cientistas, é que o mundo da ciência está mudando. É a ciência de dados intensivos, onde milhares de dados são obtidos por instrumentos ou gerados através de simulação RC: 105297

Disponível em: https://www.nucleodoconhecimento.com.br/biologia/desenvolvimentoamazonico 
produzida por software e disponibilizada em banco de dados. A técnica e tecnologia para essa ciência de dados intensivos demanda que o Estado estimule desenvolvedores, designers e pesquisadores à construção de aplicações multimodais, centrado no usuário para que possam ser auxiliados nas suas atividades de pesquisa. Sem sombra de dúvidas, após a crise de saúde em que se vive hoje, onde espontaneamente a comunicação virtual cresceu significativamente, e deverá ser consolidada no mundo inteiro, o novo pesquisador deve ter acesso a estes novos instrumentos, aprendendo até a coletar dados para introduzi-los no banco de dados. Tais dados estão sendo considerados pelos agentes de fomentos públicos como informações que podem ser disponibilizadas em bancos de dados para sociedade, pois foram obtidos com recursos públicos, porém, o conhecimento, este sim, é do pesquisador.

\section{ALGORITMOS}

O ser humano nos próximos anos pode ser controlado por um conjunto de algoritmos de acordo com o famoso historiador e escritor Harari (2018). É comum nos negócios, na administração e em outras atividades nos defrontarmos com o que chamamos de sistema. Algumas vezes nos deparamos em frente a um caixa de uma loja com o sistema que não está funcionando e tudo fica parado. Irritados, tanto o comprador como o vendedor, mas nada podem fazer até o sistema voltar a funcionar. A situação se agrava quando este sistema, agora se transformando em inteligência artificial (IA), poderá através de biosensores ter a capacidade de manifestar-se de acordo com as emoções do ser humano ou conduzi-lo a uma situação desejada pelo operador da IA. O sistema de fato é um conjunto interativo de algoritmos, sensores, computadores e operadores.

O algoritmo é a "modelagem" de procedimentos perfeitamente definidos que conduzem à solução de um problema ou de uma situação em número de etapas

RC: 105297

Disponível em: https://www.nucleodoconhecimento.com.br/biologia/desenvolvimentoamazonico 
finitas. Estes algoritmos não necessariamente são representados por modelos matemáticos, mas por procedimentos bem definidos para se conquistar uma meta (MEDEIROS et al., 2019). Por exemplo, o caminho de casa até a faculdade pode ser estabelecido como rotas a serem percorridas que podem ser simplesmente escritas; no entanto, havendo alternativas considerando o trânsito, custo etc., a solução fica mais fácil modelando matematicamente e ponderando todas as variáveis para enfim tomar a decisão para que se alcance a meta de forma mais rápida e com menor custo. Para isto, são utilizados algoritmos com o emprego de recursos matemáticos não utilizados comumente nas aulas, ou seja, a teoria de grafos que estuda a relação entre os objetos de um determinado conjunto. Os objetos considerados nesta teoria são chamados de vértices, e a relação que os liga e suas ponderações de caminhos. Por exemplo: $O$ desenvolvimento de soluções em um algoritmo científico, buscando de forma iterativa e interoperável melhorar o conjunto de hipóteses e possíveis soluções, considerando os aspectos cíclicos e contínuos. Para Goodman (2016), a iteração do algoritmo consiste em selecionar conjuntos de variáveis do problema e otimizá-las nas soluções da população, aliás cabe um certo paralelismo procedimental.

A modelagem influencia no processo de otimização, onde tal processo é uma busca estocástica com viés, pela sua abordagem inicialmente cíclica (loop) ou no seu foco no problema ainda que com restrições de dimensões de resultados (efetividade).

Vejamos o problema do caixeiro viajante (PCV), a resolutividade embarca nos aspectos da forma quantitativa de soluções, seja pelo entendimento das ponderações de grado ou pelo custo das ligações (caminhos) dos vértices.

Em Ottoni et al. (2018) uma solução para o PCV pode ser demonstrada pela sequência de vértices visitados no grafo, vale ressaltar que qualquer método construtivo pode ser usado para gerar as soluções iniciais, inclusive a geração aleatória, porém de

RC: 105297

Disponível em: https://www.nucleodoconhecimento.com.br/biologia/desenvolvimento$\underline{\text { amazonico }}$ 
forma geral, tem-se as respostas com base em dois paradigmas, o simétrico e o assimétrico. O primeiro está relacionado ao custo de deslocamento, e o segundo o sentido de realização da rota pode alterar o valor da distância total percorrida.

Como o PCV está afeto à discussão do melhor caminho a ser seguido pela ciência? É que as possíveis soluções estão no formato de redes sociais e técnicas (grados científicos). A noção de rede de atores contempla um plano de conexões heterogêneas a partir do qual emergem tanto as ciências quanto as crenças etc. Uma rede é construída por múltiplas conexões, múltiplas entradas e por múltiplos resultados, e com isso anulam-se caminhos restritivos e ficam mais eficientes.

O que está em jogo não é a resolutividade do problema, e sim o ponto de vista do observador e todas as consequências inerentes à sua decisão. O outro lado é a forma de indexação que nos possibilita organizar as reflexões e assimetrias, seja do problema, seja dos caminhos a serem tomados, e tal fato é muito importante para evitarmos processos contínuos não-efetivos.

No âmbito científico, nem sempre a indução tem compasso no processo de observação, indexação e sobretudo da resolução. E as evidências desta assertiva estão nos fatos da inépcia da análise de conteúdo dos modelos de dados, na insignificância nomológica e na estrita falta de confiabilidade (alpha de cronbach ou dillon), e, portanto, inibem o papel da objetividade, em detrimento do processo e não da resolução em si. Vale o registro da necessidade latente das validações discriminantes e convergentes.

E ainda, a ocorrência da recursividade algorítmica que está inserida na baixa efetividade dos projetos, e que tal anomalia circunscreve dois aspectos: o primeiro, relacionado com a falta de institucionalização e suas consequências; o segundo, pelo excesso de disfunção burocrática. Podemos perceber que a lógica do PCV, ou sua morfologia, alcança as estruturas da ciência, que dependendo do contexto ela não

RC: 105297

Disponível em: https://www.nucleodoconhecimento.com.br/biologia/desenvolvimento$\underline{\text { amazonico }}$ 
encontrará modelos adequados, e infalíveis, de geração de conhecimento, permeando modelos com indicadores de Cohen $\left(\mathrm{f}^{2}\right)$ extremamente baixos.

Uma consequência danosa é a baixa interoperabilidade da ciência, não somente com os atores sociais, mas principalmente com a rede institucional de pesquisa, resultando na baixa semântica dos dados gerados, trazendo à baila projetos de pesquisas desafetos à problemática local e de baixo impacto, e assim como o PCV, perdem-se na discussão da simetria, que de certa forma seria simples já que um grafo possui 4 vértices e 6 arestas invariavelmente.

A análise de interoperabilidade pode ser feita por meio de uma analogia dos grafos para problemática cientifica. À guisa de exemplo, apresentam-se diversas trilhas que podem ser feitas para criar uma rede entre atores que possam responder com maior eficiência a demanda de pesquisas. Os atores envolvidos partem do conceito de tríplice hélice para um ecossistema de inovação acrescentando mais atores que precisam participar do processo, tratando -se de pesquisas na Amazônia (Fig.2). 
Figura 2 - Plano de utilização de recursos para pesquisa, desenvolvimento e inovação
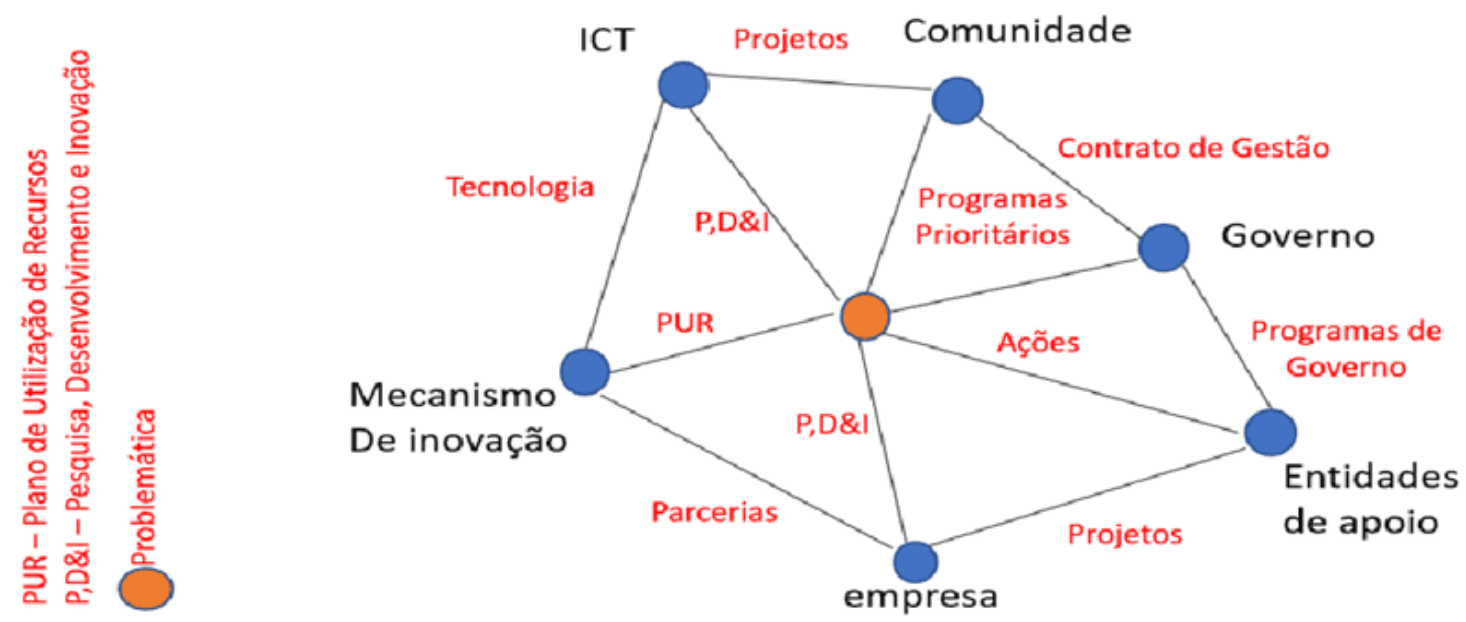

Fonte: autores.

O gráfico apresentado permite fazer uma matriz de adjacência e ponderar cada um dos atores dependendo do objetivo da pesquisa a ser desenvolvida. Por exemplo: No desenvolvimento de pesquisa de cunho mais social é possível que não seja contemplada empresa. Torna-se admissível, portanto, conhecer os atores mais pertinentes ao projeto e o encaminhamento mais adequado para que a pesquisa tenha um resultado de maior efetividade.

$\mathrm{Na}$ ciência com a inovação tecnológica de sensores e biosensores, que disponibilizam um grande volume de dados de diversas variáveis em tempo real, cujas análises e ponderações destes dados, feitos de forma sistemática, podem ser manipuladas por algoritmos científicos que, colocados em linguagem de máquina, facilitam o processamento dos dados e disponibilizam aos usuários as informações necessárias para tomada de decisão.

RC: 105297

Disponível em: https://www.nucleodoconhecimento.com.br/biologia/desenvolvimentoamazonico 
Atualmente, sem se perceber, é este o caminho adotado pela meteorologia, pelos estudos feitos sobre clima, nos corpos d'água e em algumas áreas da saúde. Isto tem alguns aspectos extremamente positivos:

a) Os dados e informações passam a ter "diálogo" com o pesquisador ou o usuário do sistema;

b) É possível nos estudos incorporar muito mais variáveis, ou seja, ampliar o universo da pesquisa, possibilitando ter resultados mais robustos;

c) As pesquisas feitas pelo ser humano serão muito menos invasivas ao meio ambiente, incluindo a fauna, do que é atualmente;

d) Na área da saúde é possível que cada ser humano tenha o seu próprio algoritmo para o monitoramento de sua saúde em tempo real com antecipação de eventuais doenças graves.

e) Finalmente, é provável que o ser humano nos próximos anos poderá superar facilmente os 80 anos de idade, sendo acompanhado em tempo real, e sendo orientado sobre o que comer e que comportamento deve ter para alcançar longevidade.

\section{O PAPEL DOS NÚCLEOS DE INOVAÇÃO TECNOLÓGICA INSTITUCIONAIS (NIT)}

Uma das mais limitantes dificuldades acadêmicas diz respeito a visibilidade do que está sendo realizado nas instituições de pesquisas. Em países desenvolvidos, as instituições contam com instâncias divulgadoras muito ativas, as quais ministram visibilidade às publicações, fato que suscita o encontro de possibilidades inovadoras às empresas, gerando dinâmica econômica. Nesse cenário, a cooperação entre a

RC: 105297

Disponível em: https://www.nucleodoconhecimento.com.br/biologia/desenvolvimentoamazonico 
universidade, empresa e governo corrobora para que as tecnologias saiam das bibliotecas das instituições e cheguem à sociedade (AGUSTINHO et al., 2018).

A promoção de sinergias beneficia a sociedade como um todo; os governos buscam desenvolvimento com acréscimos econômicos de forma a criar benefícios sociais, as universidades correm na produção de conhecimentos que acresçam o corpo de ciência existente, mas, que muitas vezes permanecem na própria academia sem qualquer contextualização, e as empresas necessitam sobreviver no mercado competitivo objetivando a lucratividade. Assim, o encontro dessas vertentes pode ser facilitado através dos núcleos de transferência tecnológica (NIT).

Agustinho et al. (2018) afirmam que os economistas dividem o processo de inovação em três fases: invenção (a ideia potencialmente aberta para exploração comercial), inovação (exploração comercial) e difusão (propagação de novos produtos e processos pelo mercado). Obviamente, o trabalho exercido pelo NIT é fulcral, pois a divulgação tecnológica é a forma como as inovações se propagam em direção ao mercado. A difusão da inovação prestada pelo NIT pode efetivamente trazer impacto no sistema econômico.

Silva, et al. (2015) analisam o processo de transferência de tecnologia entre Universidade-Indústria nos NITs das universidades públicas do Estado do Paraná, onde assinalam uma série de advertências para melhorar o desempenho da referida instância.

Um dos itens diz respeito ao incremento da capacidade empresarial para acompanhar mudanças provocadas por novas tecnologias, de modo a aprimorar produtos ou incorporar inovações. Sem dúvida, os NITs deverão aprimorar suas relações com as empresas, buscando ver quais gargalos tecnológicos poderão ser equacionados nas instituições de pesquisas; NITs carecem de sensibilidade para perceberem 
necessidades inovativas, estimulando a criatividade da academia que resultará em inovação benfazeja ao bem-estar socioeconômico.

Também é parte da rotina dos NITs a promoção de interações institucionais no âmbito acadêmico, com vista à formação de grupos especiais de pesquisas e desenvolvimento de inovações, cuja dinâmica seja translacional. Assim, devem ser pensados estímulos intelectuais com inclusão de jovens pesquisadores. $\mathrm{O}$ desenvolvimento de ambiente de cooperação exige atenção especial, uma vez que necessariamente lida com interesses da academia e das empresas. Todavia, cabe aos NITs o estímulo para o treinamento ao ambiente translacional.

Agustinho et al. (2018) ponderam que os pesquisadores nas universidades devem encarar a cooperação com a indústria como uma habilidade organizacional essencial. Certamente, os NITs poderão desenvolver mecanismos eficazes para consolidar essa cooperação.

Por outro lado, os NITs deverão buscar maior interação com o governo, para facilitar fundraising, especialmente visando o financiamento de pesquisas oriundas de demandas das crises. Uma das dificuldades brasileiras é a carga burocrática relativa à proteção intelectual e transferência tecnológica, tanto em ambiente nacional como internacional. Há de se buscar mais agilidade burocrática, uma ação política que pode ser desencadeada pelos NITs.

Os avanços da inovação e patentes no âmbito do governo brasileiro aconteceram quando, no início do ano 2000, o governo brasileiro estruturou as suas instituições de ensino e pesquisa com a implantação do Núcleo de Inovação Tecnológica e a regulamentação da lei de patente. Apesar dessas iniciativas extremamente importantes, faltaram observar alguns itens para obtenção de sucesso, tratando-se principalmente de pesquisas na área dos recursos naturais. O acesso ao patrimônio natural por meio do Conselho de Gestão do Patrimônio Genético (CGen); o tempo de

RC: 105297

Disponível em: https://www.nucleodoconhecimento.com.br/biologia/desenvolvimentoamazonico 
obtenção de patentes, que chega até 10 anos e finalmente a questão cultural de pesquisadores com mais de 50 anos.

\section{CONSIDERAÇÕES FINAIS}

Apesar do esforço amazônico na produção de conhecimento científico robusto, as demandas complexas ainda não podem contar com respostas categóricas, por força da adesão muito tímida da metodologia translacional, pela academia local. De outro lado, a influência dos resultados científicos sobre os tomadores de decisões poderia ser mais permanente se fosse adotado um certo ativismo científico, de modo a tornar mais visíveis soluções, que muitas vezes são de pronta utilização, mas, acabam trancadas nas bibliotecas das universidades.

Um dos indicadores de que os resultados persistem na disciplinaridade é escassez de editais que incentivem a formação de grupos de pesquisas translacionais que, por sua vez, permitam as modelagens matemáticas, que são as vias mais rápidas a oferecer alternativas para o gerenciamento da governança, especialmente na Amazônia. Essa ferramenta sempre oferece cenários com alta confiabilidade probabilística, sendo respaldo importante às decisões de cunho político. Porém, essa dimensão está ainda embrionária, sendo que os programas de graduação e pós-graduação amazônicos não enxergaram o quão premente é sua adoção. Além disso, o diálogo entre os vários grupos de pesquisas regionais é ainda tangencial. Não há programas estruturantes para a aproximação das instituições e produção de resultados translacionais, uma tarefa que poderia ser capitaneada pelas Fundações de Amparo à Pesquisa regionais.

Os espaços abertos entre a academia e os setores sociais, deveriam ser intensificados para que o diálogo ocorresse de forma ininterrupta. Os núcleos de transferência tecnológica (NIT) que são as janelas adequadas ao referido diálogo atuam, no caso amazônico, em velocidade reduzida, mas poderiam ser lócus de indução de inovações e atração de recursos às pesquisas, de modo a incentivar o RC: 105297

Disponível em: https://www.nucleodoconhecimento.com.br/biologia/desenvolvimento$\underline{\text { amazonico }}$ 
surgimento de parques tecnológicos e, consequentemente, progresso socioeconômico.

\section{REFERÊNCIAS}

AARON, H. J. Politics and the Professors: The Great Society in Perspective. Washington, Brookings Institution, 1978.

AGUSTINHO, E. O.; GARCIA, E. N. Inovação, Transferência De Tecnologia e Cooperação. Direito e Desenvolvimento, v. 9, n. 1, p. 223-239, 2018.

BALSIGER, P.W. Supradisciplinary research: history, objectives and rationale. Futures, v.36, n.4, 407-421, 2004.

BASSETT, M. T. Tired of science being ignored? Get political. Nature, v. 337, 2020.

BRANDÃO, R. V.; ARAUJO, I. S.; VEIT, E. A. A Modelagem Científica Vista como um Campo Conceitual. Caderno Brasileiro de Ensino de Física, v.28, n.3, 507-545, 2011.

BUNGE, M. La ciencia, su método y su filosofia. Buenos Aires: Ediciones Siglo Veinte, 1960.

BUNGE,M. La investigación científica: su estrategia y su filosofia. Barcelona: Editorial Ariel, 1989.

CARNEIRO, M. J. T.; SANDRONI, L. T. Ciência e política pública na perspectiva dos gestores: clivagens e confluências. Revista Sociedade e Estado, 41-61, 2018.

RC: 105297

Disponível em: https://www.nucleodoconhecimento.com.br/biologia/desenvolvimento$\underline{\text { amazonico }}$ 
CENTRE FOR EDUCATIONAL RESEARCH AND INNOVATION (CERI). Interdisciplinarity: Problems of Teaching and Research in Universities. Paris: Organization for Economic Co-operation and Development, 1972.

FACULDADE DE MEDICINA DA UNIVERSIDADE FEDERAL DE MINAS GERAIS. Belo Horizonte: Faculdade de Medicina, 2021. Disponível em: https://www.medicina.ufmg.br/nova-perspectiva-da-pesquisa-em-tempo-real/ acesso em 23 outubro 2021.

FACULDADE DE MEDICINA DA UNIVERSIDADE FEDERAL DE MINAS GERAIS. Nova perspectiva da pesquisa em tempo real. Belo Horizonte: Faculdade de Medicina da UFMG, 2020. Disponível em: https://www.medicina.ufmg.br/novaperspectiva-da-pesquisa-em-tempo-real/ Acesso em 21 de outubro 2021.

FALCÃO, I. Entenda a evolução das pesquisas com células-tronco no mundo. Agência Brasil, $2005 . \quad$ Disponível http://memoria.ebc.com.br/agenciabrasi//noticia/2005-02-02/entenda-evolucao-daspesquisas-com-celulas-tronco-no-mundo Acesso em 15 de outubro 2021.

GOODMAN, Bryce W. "A step towards accountable algorithms? Algorithmic discrimination and the European Union general data protection." 29th Conference on Neural Information Processing Systems (NIPS 2016), Barcelona. NIPS Foundation. 2016.

GUNDERSON, M. How Academic Research Shapes Labor and Social Policy. Journal of Labour Research, 1-33, 2007.

HARARI, Y. N. Homo deus: uma breve história do amanhã. Rio de Janeiro: Editora Companhia das Letras, 2018. 
HEINEMAN, R. A.; BLUHM, W. T.; PETERSON, S. A.; KEARNY, E. N. The World of the Policy Analyst: Rationality, Values and Politics. Chatham, NJ: Chatham House Publishers, 1997.

HEY, T.; TANSLEY, S.; TOLLE, K. (orgs.). O Quarto Paradigma: descobertas científicas na era da eScience. São Paulo: Oficina de Textos, 2011.

INSTITUTO PARA O DESENVOLVIMENTO DO JORNALISMO. A ideologização da ciência. Observatório da Imprensa, 2015. Disponível em: http://www.observatoriodaimprensa.com.br/ciencia/a-ideologizacao-da-ciencia/ Acesso em 15 de outubro 2021.

JUSTI, R. S.; GILBERT, J. K. Modelling, teachers' views on the nature of modelling, and implications for the education of modellers. , v. 24, n. 4, p. 369-387, 2002.

KUHN, T. S. The Structure of Scientific Revolutions. Chicago: University of Chicago Press, 2012.

LAWRENCE, R.J. Housing and health: from interdisciplinary principles to transdisciplinary. Futures, v. 36, n. 4, p. 487-502, 2004.

LAWRENCE, R. J.; DESPRÉS, C. Futures of Transdisciplinarity. Futures, v. 36, n. 4, p. 397-405, 2004.

LEFF, E. Saber ambiental: sustentabilidade racionalidade, complexidade, poder. Rio de Janeiro: Vozes, 2002.

LOMBARDI, M. F. S.; BRITO, E. P. Z. Incerteza Subjetiva no Processo de Decisão Estratégica: uma Proposta de Mensuração. Revista de Administração Contemporânea, p. 990-1009, 2010.

RC: 105297

Disponível em: https://www.nucleodoconhecimento.com.br/biologia/desenvolvimento$\underline{\text { amazonico }}$ 
LYNCH, Lisa. Job Loss: Bridging the Research and Policy Discussion. IZA Discussion Paper, p. 1518, 2005.

MAFFESOLI, Michel. O Tempo das Tribos. O Declinio do Individualismo nas Sociedades de Massa. Rio de Janeiro: Forense Universitária, 1998.

MEDEIROS, Dianne SV et al. Análise de dados em redes sem fio de grande porte: Processamento em fluxo em tempo real, tendências e desafios. Sociedade Brasileira de Computação, 2019.

MITRE, M. As relações entre ciência e política, especialização e democracia: a trajetória de um debate em aberto. Estudos Avançados, v.30, n.87, p. 279-298, 2016.

OGBURN, E. L.; BIERER, B. E.; BROOKMEYER, R.; CHOIRAT, C.; DEAN, N. E.; GRUTTOLA, V.; ELLENBERG, S. S.; HALLORAN, M. E.; HANLEY Jr, D. F.; LEE, J. K.; WANG, R.; SCHARFSTEIN, D.O. Aggregating data from COVID-19 trials. Science, v.368, n.6496, p.1198-1199, 2020.

OTTONI, A.L.C.; NEPOMUCENO, E.G.; OLIVEIRA, M.S. A response surface model approach to parameter estimation of reinforcement learning for the travelling salesman problem. Journal of Control, Automation and Electrical Systems, v.29, n.3, p. 350359, 2018.

RAMADIER, J. Transdisciplinarity and its challenges: the case of urban studies. Futures, v. 36, n. 4, p. 423-439, 2004.

SILVA, J. A.; BIANCHI, M. L. P. Cientometria : A Métrica da Ciência. Paidéia, p. 5-10, 2001.

RC: 105297

Disponível em: https://www.nucleodoconhecimento.com.br/biologia/desenvolvimento$\underline{\text { amazonico }}$ 
SILVA, L. C. S.; KOVALESKI, J. L.; GAIA, S.; SEGUNDO, G. S. A.; CATEN, C. S. T. Processo de transferência de tecnologia em universidades públicas brasileiras por intermédio dos núcleos de inovação tecnológica. Interciencia, v.40, p. 664-669, 2015.

ZULUAGA, C. G. La investigación como ejercicio para saber y para vivir. Perseitas, v.5, p. 272-275, 2017.

Enviado: Julho, 2021.

Aprovado: Janeiro, 2022. 